\title{
Problems in waste management in the aspect of the secondary use of plastics from WEEE
}

\author{
Katarzyna Kapustka ${ }^{1, *}$, Gerhard Ziegmann ${ }^{1}$, and Dorota Klimecka-Tatar ${ }^{2}$ \\ ${ }^{1}$ University of Technology, Clausthal Centre of Material Technology, Agricolastraße 2, 38678 \\ Clausthal-Zellerfeld, Germany, EU \\ ${ }^{2}$ Czestochowa University of Technology, Department of Production Engineering and Safety, \\ ul. Armii Krajowej 19 B 42-200 Czestochowa, Poland, EU
}

\begin{abstract}
Waste of electrical and electronic equipment is one the fastest growing waste streams in the EU, with some 9 million tonnes generated in 2005 and expected to grow to more than 12 million tonnes by 2020 . Electrical and electronic products contain substances, which are valuable as well as often also critical. The main aim of the paper is presentation the methodological approach to identification of bromine or chlorine presence in components (in WEEE). This followed by assessment of strengths and weaknesses of the most popular methods. The main analysis for identification of bromine and chlorine in plastics have been presented.
\end{abstract}

\section{Introduction}

The production of electric and electronic equipment (EEE) is one of the fastest growing areas, it has resulted in an increase waste of electrical and electronic equipment (WEEE) amount. In view of the ecological problems involved in the management of WEEE, European countries and organizations have drafted national legalisation to improve the reuse, recycling and other forms the point of waste treatment but also from recovery of valuable materials. Electrical and electronic products contain substances, which are valuable as well as often also critical (e.g. mass metals: copper, aluminium etc., precious metal: gold, silver etc., critical metals: indium, gallium etc.) and pose risks to the environment and human health (e.g. heavy metals: mercury, cadmium etc., flame retardants: pentabromophenol etc.) [1,2]. On the other hand, waste management, in WEEE area, gives the opportunity to re-use elements, the occurrence of which is quite limited, and the technology of production is expensive and complicated. Such an example may be the reprocessing of magnetic materials based on rare earth elements from electric motors and hard disk [3]. Therefore, the management of electro-intangible has become one of the important cognitive aspects, aims to combine the experience of engineering sciences with collecting and separation in the field of electronic waste management [4]. In Europe, exist high political interest for converting waste into a resource and a proper management of this waste flow. While secondary plastics increase at the process are largely redirected to the manufacture due to their high fraction purity, secondary plastic waste accruing after product

* Corresponding author: katarzyna.kapustka@tu-clausthal.de 
use is recovered on a significantly smaller scale. The energetic recovery of plastic waste is still dominant in European country.

\section{Global production of plastics and WEEE generation}

This is in clear contradiction with the emerging circular economy policy framework where the value of products, materials and resources is maintained in the economy for as long as possible $[5,6]$. In 2014, the world production of plastics was 270 million tonnes (Mt), with an EU production and demand of $50 \mathrm{Mt}(18.5 \%)$ and $49 \mathrm{Mt}$, respectively and $2.8 \mathrm{Mt}(5.8 \%)$ of this EU production used for electric and electronic equipment. The waste of electric and electronic separately collected in 2013 reached $3.5 \mathrm{Mt}$ (6.5 kg/inhabitant), of which $2.7 \mathrm{Mt}$ were recovered. The plastic fraction in European WEEE depends on categories and products and was estimated to be $2.3 \mathrm{Mt}$ or about $20.6 \%$ of the weight of EEE in 2008 [7]. The mass flow of recycled plastics from WEEE separately sorted in the EU can be estimated to $0.48 \mathrm{Mt}$ (0 $2.4 \mathrm{Mt}$ WEEE recovered/ 20\% plastics in WEEE). It is worth noting that in WEEE the flame retardant (FR) additives are also found - chlorinated and brominated organic compounds or polymers are mixed with the plastics used in electric and electronic equipment to prevent fire damage. On average, $30 \%$ of the plastics in EEE contain FRs and halogenated compounds [8-10]. The life cycle environmental impacts of post-consumer plastics production from mixed plastic-rich WEEE treatment residues from perspective of the customers delivering the residues and the customers buying the obtained post-consumer recycled plastic is clearly superior to the alternatives (i.e. municipal solid waste incineration (MSWI) and virgin plastics production) [6].

Directive 2012/19/EE of European Parliament and of the Council on waste electrical and electronic equipment (WEEE Directive) aims to address this issue by implementing inter alia the principle of the extended producer responsibility and collection, recovery as well as joint recycling/preparing for reuse targets (Art. 11, Directive 2012/19/EU). The Commission implemented Regulation 2017/699 validating a regular methodology for: the calculation of the weight of EEE placed on the national market. In 2017, the Commission adopted a legislate proposal to introduce the use of substances in electrical and electronic equipment as hazardous. The activities provides for the creation of collection schemes where consumers return their used waste EEE free charge. The objective of these schemes is to increase the recycling and re-use of such products (Fig.1).

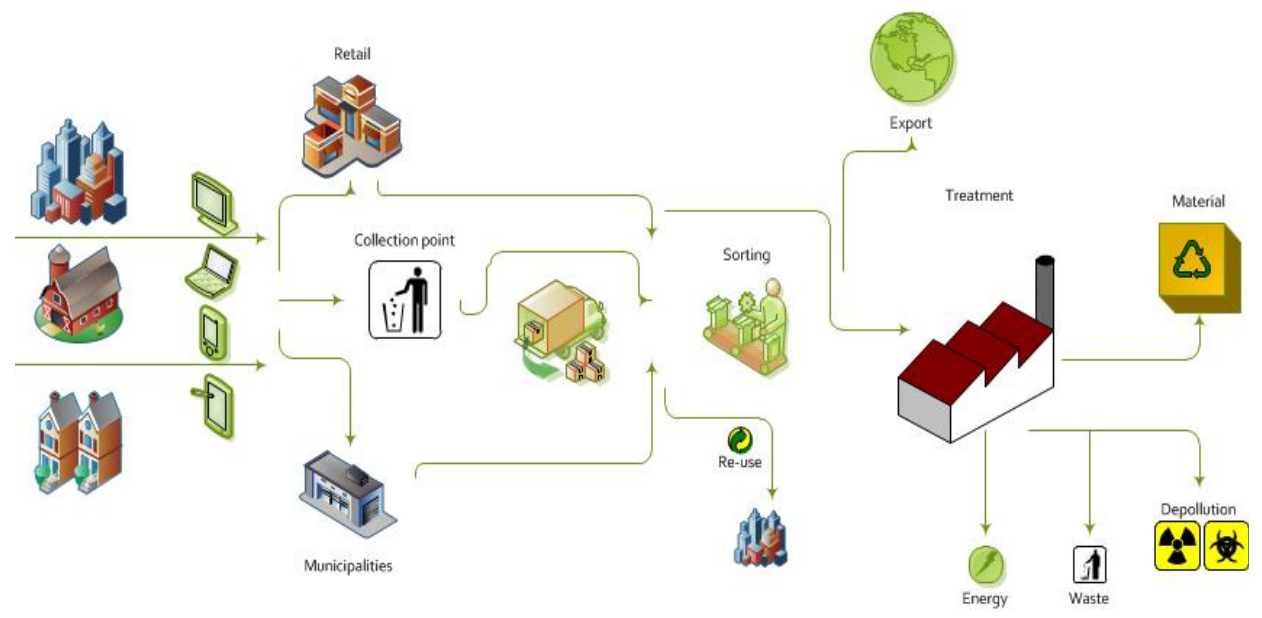

Fig. 1. Circuit diagram, from electric and electronic equipment (EEE) through waste of electrical and electronic equipment (WEEE) to recycled material. 


\section{Management of materials obtained from WEEE}

The WEEE is called the mixture of materials and components due their hazardous content, and if not properly utilize, can cause major environmental and health problems. The role of WEEE utilization management is improvement of resource by increased collection, transformation and recycling of electronics at the end of their life is essential. Secondary market operations for EEE, which involve repair, replacement of spare parts, refurbishment and reuse, and retrofitting, should be facilitated to promote a circular economy in the Union [11]. Besides the problem of low collection rates, the recycling of plastics are very low [12 14]. Plastics are a considerable fraction of WEEE and contributes to the total generation of post-consumer plastic waste in the EU-27, Norway and Switzerland in 2008 at 5\% [15], but the presence of brominated flame retardants (BFR) as well as various plastic types and missing incentives (e.g. economic benefits of energy recovery) hampers the recycling of plastic obtained from WEEE $[7,13]$. The high halogen content in theses plastics with respect to their end of life management are the reasons the popular environmental and health issue problem. In fact, halogenated plastics under heating treatment can release irritant and corrosive gases, such as $\mathrm{HCl}$ or $\mathrm{HBr}$. Also, in the presence of oxygen, metal oxides in the ashes, and temperatures between 200 and $500^{\circ} \mathrm{C}, \mathrm{HCl}$ and $\mathrm{HBr}$ can be possible precursor of toxic substances such as polyhalogenated dioxins and furans and various other organic halogen compounds [16]. Equal if they undergo pyrolysis, a thermal treatment at low temperatures under inert atmosphere, dehalogenation of pyrolysis oil and gas is essential to make them commercially sufficient. For these reasons, quality parameters of WEE plastics is depend on the concentrations of bromine and chloride.

\section{Analysis of bromine and chlorine presence in WEEE plastics}

Sample pre-treatment followed by gas chromatography-mass spectrometry (GC-MS) is instrumental analysis technique used to distinguish restricted from non-restricted BFRs and for their density $[17,18]$. Pre-treatment let on a complete dissolution of the polymer in an relevant solvent, normally at room temperature, in sequence to avoid the thermal degradation of BFR $[19,20]$. Alternatively, a solid-liquid extraction is often adopted along with a series of extraction procedures, such as those performed by shaking, ultrasonication, microwave extraction, pressurized solvent, and supercritical $\mathrm{CO}_{2}$ [20-25]. In addition to GC-MS, other analytical techniques used after the sample pretreatment and high performance liquid chromatograpy coupled with MS or UV detector, infrared analysis, and GC with an electron capture detector [21, 26-28]. When the BFRs are copolymerized into the backbone of the polymer, their separation and quantification by the methods can be very complicated to achieve [29,30]. Unfortunately, as the sample amount to be subjected to pyrolysis is very small (less than $1 \mathrm{mg}$ ), this technique is not appropriate for heterogeneous plastic waste [31]. Furthermore, some pyrolysis products may negatively affect the results of the analysis and identification of all the compounds.

The alternative destructive but quite simple analysis that could be identically used for plastic materials is the elemental analysis of chlorine and bromine by ion chromatography (IC) or titration. The analysis consists of high-pressure oxygen bomb combustion of the sample followed by halogens recovery in a basic suspension $[32,33]$. Methods based upon non-destructive technics bring a useful perspective to check the eventual presence of bromine and chlorine. They involve infrared equipped with an attenuated total reflectance accessory, energy dispersive X-ray fluorescence spectroscopy (ED-XRF) and Raman spectroscopy [18, 21, 34, 35]. ED-XRF presents elementary results for bromine and chlorine, while Raman spectroscopy or infrared spectroscopy can be helpful in determining 
specific halide compounds. Kikuchi et al. in their research [35] indicated that BFRs in acrylonitrile butadiene styrene (ABS) that Raman spectroscopy is less sensitive to matrix interference, the results are greatly affected by this problem, which may mask the results, in particular for small compound contents [18]. Morf et al. published a quantitative XRF analysis [36], has been implemented on grained samples mixed with a matrix modifier (silicates and/or lime), for calibration used a similar matrix (stand on a calibration for geological samples with standard reference material). Although Aldrian et al. assessments a handled XRF [37], provided with the manufacturer's software, for a quantitative analysis on WEEE. Many authors observed the importance of routine calibration of the XRF analyser [33], as in the case of manufacture installed elemental rates are appreciably different from calibration standards. To conclude, the lack of standards with matrices as identical as possible to those of the samples can lead to less exact results. Consequently, it might be profitable to investigate the results secured by using more authoritative laboratory methods, and regard XRF as a very usable checking test for determining elemental concentration $[33,38]$. In table 1 the concentration of bromine and chlorine based on results reported in literature are presented.

Table 1. Review of $\mathrm{Cl}$ and $\mathrm{Br}$ analysis of WEEE plastics by different techniques [38-41].

\begin{tabular}{|c|c|c|c|}
\hline $\begin{array}{c}\text { Type of obtained plastic } \\
\text { material }\end{array}$ & $\mathrm{Br}, \%$ & $\mathrm{Cl}, \%$ & $\begin{array}{c}\text { Possible methods } \\
\text { of analysis }\end{array}$ \\
\hline TV and monitors & $0.01-1.3$ & $0.01-10.6$ & Semiquantitative XRF \\
\hline $\begin{array}{c}\text { small household } \\
\text { appliances - small WEEE }\end{array}$ & 4.5 & 1.2 & $\begin{array}{c}\text { Not mentioned } \\
\text { HXRF } \\
\text { XRF ICP-OES }\end{array}$ \\
\hline WEEE & 1.3 & $0.02-3.9$ & $\begin{array}{c}\text { Total reflection XRF } \\
\text { HXRF }\end{array}$ \\
\hline $\begin{array}{c}\text { Cooling devices - fridge } \\
\text { freezers }\end{array}$ & - & IC \\
\hline
\end{tabular}

According to literature data in the plastic obtained from the small pieces of household equipment (small WEEE) identified even $4.4 \%$ of $\mathrm{Br}$ and $1.2 \mathrm{of} \mathrm{Cl}$, while in waste from TV and $\mathrm{PC}$ even $10.6 \% \mathrm{Cl}$ [38-41]. Such high contents bromine and chlorine in plastic material obteined from differend kind of WEEE make these materials particularly demanding in terms of processing and disposal.

\section{Summary}

Literature review and familiarization with the basic legal acts force in Europe, allows to draw the conclusion, that waste management is a strategic point in the development of materials management. It can be noticed that the significant development of civilization contributes to the increase in the number of manufactured goods (in particular electrical and electronic equipment), which service is limited and, as a consequence, increases the number of waste. Difficulties arising from the recovery of WEEE materials arise from the complexity of this waste. WEEE is called the mixture of materials and components due their hazardous content, and if not properly utilize, can cause major environmental and health problems. The most difficult material to recover are polymeric materials, and in particular those that contain bromine and chlorine in chemical composition. The high halogen content in WEEE plastics with respect to their end of life management are the reasons of the popular health problem, cause the product of precursor of toxic substances such as polyhalogenated dioxins and furans and various other organic halogen compounds. 
Therefore, methods are sought for easy identification of chemical components in plastic waste, which will allow quick reactions to WEEE utilization.

\section{References}

1. B.H. Robinson, Sci. Total. Environ., 408(2), 183 (2009)

2. O. Tsydenova, M. Bengtsson, Waste Manag., 31(1), 45 (2011)

3. K. Kapustka, G.Ziegmann, D.Klimecka-Tatar, Production Engineering Archives 17, 36 (2017)

4. M. Ingaldi, S. Jursovà, METAL 2013: 22nd International Conference On Metallurgy And Materials (TANGER, Ostrava, 1779, 2003)

5. European Commission. Communication from the Commission to the European Parliament, the Council, the European Economic and Social Committee and the Committee of the Regions - Closing the loop - An EU action plan for the Circular Economy [Internet]. Brussels, Belgium, (2015)

6. P. Wäger, R. Hischier, Sci. Total. Environ., 529, 158 (2015)

7. Plastic Europe, Plastics the facts 2016 (2017)

8. BMUB. Elekro - und Elektronikgeräte in Deutschland: Daten 2009 und 2010 zur Erfasung, Behandlung und Wiederverwendung [Internet] (2013)

9. H. Wilts, N. von Gries, I. Dehne, R. Oetjen-Dehne, N. Buschow, J. Sanden. Entwicklung von Instrumenten und Maßnahmen zur Steigerung des Einsatzes von Sekundärrohstoffen - mit Schwerpunkt Sekundärkunststoffe (Report No., FKZ 3712933 340)

10. M. Alaee, P. Arias, A. Sjödin, A. Bergman. Environ. Int., 29, 683 (2003)

11. M. Bientinesi, L. Petarca. Waste Manag., 29, 1095 (2009)

12. R. Widmer, H. Oswald-Krapf H. D. Sinha-Khetriwal, M. Schnellmann, H.Böni. Environ. Impact Assess. Rev., 25, 436 (2005)

13. Directive of the European Parliament and the Concil amending Directive $2011 / 65 / \mathrm{EU}$ on the restriction of the use of certain hazardous substances in electrical and electronic equipment (2017)

14. J. Baxter, M. Wahlstrom, M. Zu Castell-Rüdenhausen, A. Frane, M.Stare, S.Lokke, et al. Plastic value chains: Case: WEEE (Waste Electric and electronic equipment) in the Nordic region (Nordic Council of Ministers 2016)

15. J. Huisman, P. Leroy, F. Tertre, M. Ljunggren, et al., Prospecting Secondary Raw Materials in the Urban Mine and mining waste (ProSUM)- Final Report, (Brussels, Belgium, 2017)

16. H. Friege, Waste Manag. Res., 30, 3 (2012)

17. B. Beccagutti, L. Cafiero, M. Pietrantonio, S. Pucciarmati, Sustainability-Basel, 8, 1101 (2016)

18. M. Brebu, T. Bhaskar, A. Muto, Y. Sakata, Chemosphere, 64, 1020-1025 (2009)

19. E. Plinke, N. Wenk, G. Wolff, D. Castiglione, M. Palmark, Mechanical Recycling of PVC Waste, Study for DGXI of the European Commission (B43040/98/000821/MAR/E3) (European Commission, Brussels, Belgium, 2001)

20. S. Kemmlein, D. Herzkeb, R.J. Law, J. Chromatogr, 1216, 320 (2009)

21. S. Hamm, M. Strikkeling, P. Ranken, K. Rothenbacher, Chemosphere, 44, 1353 (2001) 
22. V. Zitko, Chemosphere, 38, 629 (1999)

23. Altwaiq, M. Wolf, R. van Eldik, Anal Chim, Acta, 491, 111 (2003)

24. M. Schlummer, L. Gruber, A. Maurer, G. Wolz, R. van Eldik, Chemosphere, 67, 1866 (2007)

25. T. Imai, S. Hamm, K. Rothenbacher, Environ. Sci. Technol, 37, 652 (2003)

26. G.T. Tomy, T. Halldorson R. Danell, R.K. Law, et.al, Mass Spectrom., 19, 2819 (2005)

27. B. Binici, M. Bilsel, M. Karakas, I. Koyuncu, A.C. Goren, Talanta., 116, 417 (2013)

28. M. Schlummer, F. Brandl, A. Mäurer, R. van Eldik, Chromatogr., 1065, 39 (2005)

29. Ballesteros-Gomez, S.H. Bdandsma J. de Boer, P.E.G Leonards, Chemosphere, 116, 10 (2014)

30. M.P. Luda, A.I. Balabanovich, M. Zanetti, D. Guaratto, Poly. Degrad., 92, 1088 (2007)

31. F.C-Y. Wang. J. Chromatogr., 866, 225 (2000)

32. J. Aguado, D.P. Serrano, G. San Migueal, J. Polym. Environ., 15, 107 (2007)

33. J.A. Onwudili, P.T. Williams, Chemosphere, 74, 787 (2009)

34. E. Dimitrakakis, A. Janz, B. Bilitewski, E. Gidarakos, Waste Manag., 29, 2700 (2009)

35. M. Riess, T. Ernst, R. Popp, B. Müller, H. Thoma, O. Vierle, M. Wolf, R. van Eldik, Chromosphere, 40, 937 (2000)

36. S. Kikuchi, K. Kawauchi, S. Ooki, M. Kurosawa, H. Honjho, T. Yagishita, Anal. Sci., 20, 1111 (2004)

37. L.S. Morf, J. Tremp, R. Gloor, F. Schupisser, M. Stengele, R. Taverna, Waste Manag., 27, 1306 (2009)

38. Aldrian, A. Ledersteger, R. Pomberger, Waste Manag., 38, 297 (2017)

39. R. Taurino, P. Pozzi, T. Zanasi, J. Anal.Chem., 368, 235 (2000)

40. B.M. Caballerom I. de Marco, A. Adrados, et. al., Waste Manag., 57, 226-234 (2016)

41. O. Sindiku, J. Babayemi, M. Schlummer, M- Schleup, A. Watson, R. Weber, Environ. Sci. Pollut. Res., 22, 14489 (2015) 